\title{
RETHINKING RESEARCH IN SOUTH SÁMI COMMUNITIES
}

\section{BY ANNE MOE AND MARIANNE HEDLUND}

\section{ABSTRACT}

In this article, we address methodological issues of conducting research in South Sámi communities. These communities belong to indigenous areas of the Norwegian and Swedish territory state and have been less explored in research. South Sámi people mostly live as a minority group in their communities. They may represent an alternative societal perspective and mobilize on other grounds than Norwegians in these settings. It is consequently necessary to be cautious when carrying out this research. In this article, we discuss a previous research project 'South Sámi and welfare services' (Hedlund \& Moe, 2000; 2010) that we conducted from a methodological point of view. The aim is to discuss how rethinking the methodology of this research project and similar projects, allows different types of knowledge and insight to be gained. In this article we discuss how an institutional ethnographic methodology may allow researchers to elaborate systematic knowledge on how South Sámi, as social subjects, act and interact with their environments and everyday life problematics. We argue that such an approach can reveal how dominant structures of the privileged majority population in these communities, influence and try to mainstream the everyday life practice of South Sámi people. We also discuss the role of research carried out in South Sámi communities and any colonising gaze that can appear if researchers belong to a majority and privileged group. What research strategies could be used to minimize this gaze and make the indigenous people's critical voices towards the dominant society rise to the surface? 


\section{INTRODUCTION}

In this article, we use our experience from a previous research project, 'South Sámi and welfare services' (Hedlund \& Moe, 2000; 2010), to reflect critically on the use of methodology in this type of project. The aim of this project was to study how public welfare services could be made more accessible to the culture and needs of the southern Sámi people who use the services. Our aim in this article is, however, to rethink the methodology of the research design used for collecting and analysing data in South Sámi communities. We ask the following questions: Which methodological choices do we need to make in this type of research? What type of power structures occur and what strategies can minimize any colonial gaze of researchers as representatives of the majority population, upon South Sámi people as minorities? The article is structured in the following way. We first introduce the South Sámi and the context. Then we present decolonisation and institutional ethnography as a possible methodological approach, and then finally discuss the impact of this on research approaches and any possible danger of carrying out research that brings forward colonisation as an unintended result.

The background for the research project described in this article is the position of Sámi in the development of Norwegian welfare state services and the position of indigenous people in Norway. Norwegian authorities have, since the mid-1990s, proclaimed the political goal that every citizen should have equal access to public health and social services, regardless of geographical, social and age-related differences. This goal was finally concretised, after a long process, in a specialised health and social plan for Sámi (NOU, 1995:6). The plan aimed to fulfil the obligations stipulated by ILO convention 169 on indigenous and tribal peoples' rights. This convention states that the Sámi are an indigenous people with their own culture and traditions. The research however shows that, despite this plan, that problems arose in the 1990s with language, with a lack of understanding and good support networks that take into account culture and traditions in public services aimed at the Sápmi landscape in Norway, in Sweden and in Finland (Daerga, Sjölander, Jacobsson, \& Edin-Liljegren, 2012; Nystad, Melhus, \& Lund, 2008; Heikkilä, 2016). There is little knowledge in Norway about the status of the welfare services offered to the South Sámi population. 
We emphasise that (in relation to the arguments presented in this article), the south part of Sápmi is less explored and researched than the northern part. The south part of Sápmi extends across large areas in the middle of Norway and Sweden. The population is, however, small, approximately 2,000 people in Norway and Sweden. The density of the South Sámi population is therefore very low (Johanson, 2006; Saeminj Sitje, 2018). South Sámi culture and language are related to and partly depend on reindeer herding, which a large proportion of the South Sámi people are involved in (Johanson, 2006).

Research on Sámi issues in the south is therefore highly needed. The small population, however, means it is methodologically and scientifically challenging. Norway has always contained multicultural communities of indigenous peoples. Attention to cultural sensitivity in welfare services and occupations has, however, only recently arisen as an issue, as it also has in modern migration and immigration in society (Governmental White Paper [St. Meld.] no 13 (2011-2012)). Greater focus on culture, including cultural understandings and competences, is today required by practitioners in the welfare state service, to ensure help and services are more accessible and appropriate to Sámi people.

\section{THE RESEARCH PROJECT: SOUTH SÁMI AND WELFARE STATE SERVICES}

The research project 'South Sámi and welfare services' (Hedlund and Moe, 2000; 2010) was financed by the Sámi Parliament, and aimed to explore experiences of encounters between South Sámi people and social and health workers. The research was carried out to gain knowledge on how the services could be better adjusted to the needs stemming from South Sámi culture and traditions. Data was gathered through a qualitative design, relying on qualitative interviews with service providers and South Sámi. We used two separate interview guides, one for the welfare professionals and one for South Sámi users of the services. The interview guides contained questions on the interviewees' professional or personal situations and experiences of encounters. Some thematic questions were the same for service providers and users. Users were in particular asked about experiences and cultural accessibility when in contact with the welfare state services.

The sample consisted of eight South Sámi interviewees and eight service providers. We also interviewed three key-informants with long and profound experience of the interaction between South Sámi people and public services. 
The sample was recruited through the snowball method, interviewees helping us find others to interview. The South Sámi were 25-70 years of age, some married, others single. All eight health and social workers were employed in two municipalities and had experience in providing services to the South Sámi people. The sample lived in five different small municipalities, the South Sámi people being a significant minority in these municipalities. Participants gave their informed consent to collect the data in the study and the study was approved by the Norwegian Social Science Data Service.

Some interviewees were active in the reindeer husbandry. Others had careers linked to this industry. Reindeer husbandry as an industry, culture and way of life is unique both nationally and internationally, but originated in Norway within the Sámi population. Today Sámi reindeer husbandry is mainly conducted in mountain pastures and rangelands in the northernmost counties of Norway, these being Finnmark, Troms, Nordland and North Trøndelag. It is also conducted in parts of South Trøndelag, Møre and Romsdal and Hedmark in Mid-Norway (Ministry of Agriculture and Food, 2019). South Sámi reindeer husbandry has kept its importance, even though the majority of South Sámi work in other industries. They, even so, strongly identify with reindeer husbandry through family and through holding on to the Sámi landscape as an element of South Sámi culture (Jernsletten, 2010).

The research project was presented orally and in writing to the Sámi Parliament (Hedlund \& Moe, 2000). The aim of the project was to provide a better knowledge base for adapted welfare services to South Sámi.

A new project was also initiated to develop the welfare service in South Sámi communities. This project focussed on disseminating knowledge from the research project to public authorities and welfare state service providers. Dissemination was through workshops, conferences and meetings in South Sámi communities. A network of health and social workers of South Sámi people was also established in this region, based on the results of the research project.

\section{PARTICULAR CHALLENGES IN SOUTH SÁPMI}

The south part of Sápmi includes the areas south of Saltfjellet in Norway and the corresponding geographic areas in Sweden. South-Sámi culture and traditions are here primarily visible in inland Norway. This area, both in Norway and Sweden, is where the Sámi population traditionally spoke the South Sámi 
language, a language that was as early as 1993 listed by UNESCO as severely endangered, because no or few children were learning the language. There has been a revitalisation of efforts in recent years to keep the language alive (Ministry of Work and Integration (AI), 2009). Three municipalities in the South Sámi area have been incorporated as Sámi administrative language areas. This imposes on the municipalities the obligation to recognize the Sámi language as being equal to the Norwegian language (Sámi Parliament, 2019). The language and culture of South Sámi was established a very long time ago, the right to learn South Sámi as a subject in school being one of the most important measures in revitalising the Sámi language (Todal, 2005). The endangered situation of the language played an important role in bringing about a change in attitude towards the South Sámi language by South Sámi people (Steinfjell, 2014).

The South Sámi area extends across a large area in the middle of Norway and Sweden. It extends from Hedmark County in the south, to part of Nordland County in the north. Municipalities such as Røros, Snåsa, and Hattfjelldal are considered to be core South Sámi areas (Johansen, 2006; Mathisen, Carlsson \& Sletterod, 2017). In Sweden, the South Sámi area includes Västerbotten County, Jämtland County and parts of Härjedalen and Dalarna County. The South Sámi population are a minority in the core areas of South Sápmi in both Norway and Sweden.

The South Sámi have traditionally pursued a variety of livelihoods. Free-grazing reindeer and semi-nomadic reindeer husbandry has been important both traditionally and in modern times to the South Sámi (Morris, 2009; Johansen, 2006). A total of 504 people were directly involved in reindeer herding in 2012, according to Hilmo \& Mæhlum (2012). A higher proportion in South Sàpmi are involved in reindeer husbandry (57\%,), than in the north (22 \%) in 2012 (Hilmo \& Mæhlum, 2012). Reindeer husbandry is a small industry at the national and regional scale, both in Norway and Sweden. The South Sámi culture is, however, considered to rest on the traditions of the semi-nomadic reindeer husbandry, this industry having played and still playing an important financial and cultural role. The reindeer husbandry industry is also recognised by the government and covered by Norwegian legislation. According to Norwegian Reindeer administrative legislation (Gauslaa, 2005), sustainable reindeer husbandry should be provided to the Sámi culture, the tradition and custom benefiting the reindeer population itself and society as a whole. Norway has, unlike Sweden, ratified the ILO 169 convention (ILO, 169). The Sámi in South Sápmi nevertheless experience many conflicts between reindeer 
husbandries and farmers (regarding pastures) and also between the Sámi and the government authority that regulates predator species (Fjellheim, 2013).

Differences between the contextual characteristics of the Northern and Southern Sápmi mean that there are differences in identity between the two (Mathisen, Carlsson, \& Sletterod, 2017). A common identity marker for 'belonging' in South Sápmi is, irrespective of this, the connection with reindeer husbandry. For some, reindeer husbandry articulates being a 'true Sámi' (Blix, Hamran, \& Normann, 2013); a cultural basis for the lifeworld of Sámi identity. Reindeer husbandry and its relation to the landscape, culture and nature historically continue to keep specific rights and a focus, as stipulated by the Norwegian constitution. This entails territorial use and rights that distinguish Sámi from Norwegians, which contributes to the formation of a collective Sámi identity (Johansen, 2006). Research shows the importance of this industry to the safeguarding of Sámi culture in South Sápmi, and to young people's choice of education, vocation and residency, and their wish to attend to family activities and traditions in these areas (Mathisen et. al., 2017).

\section{THE HISTORICAL SINS OF RESEARCH AND CONTEMPORARY CHALLENGES}

The exposure of Sámi in South Sápmi to research, may bring to the fore bad memories of racial and biological suppression. Earlier research in this landscape, such as skull measuring by scientists during the 1930s and 1940s to study the South Sámi population, may have left deep and wounding scars. South Sámi people were also exposed some years later to scientific methods in the measurement of radiation in the body and in food after the Chernobyl incident in the 1980s. Reindeer meat is a traditional part of the South Sápmi diet. The South Sápmi was therefore one of the areas at risk of sickness and ill health. This incident affected the wellbeing of South Sámi people for years to come (Furberg, Evengård, \& Nilsson, 2011; Heiervang, Mednick, Sundet \& Rund, 2011). All this, and also climate change, increased tourism and other activities on the indigenous land of South Sámi, combine with the forces of discrimination and colonisation, to bring to the fore bad collective memories of what research can do to people in South Sápmi.

We argue elsewhere how this makes research in South Sápmi complex. Precautions must be taken if researchers are part of the Norwegian majority 
group and the research target group is the South Sámi minority group (Hedlund \& Moe, 2010). Relating to indigenous people and being of indigenous descent can, according to Sehlin MacNeil (2015), create hindrances in any research context. She argues that certain precautions must be taken if research projects in which researchers and participants are of different ethnic groups, are to be successful. The research design must ensure that indigenous peoples are active participants, and have control over the issues that are relevant to indigenous peoples. The researcher and the participants must therefore work closely together throughout the research process, the hopes and fears of both must, through this, be discussed and brought to the surface. An indigenous approach to research should consider the majority's former policies of colonialism, imperialism and oppressive structures over indigenous people. An indigenous approach can ensure that the voices of indigenous people and the important contextualising concepts of the community and its nature are heard (Smith, 1999; Chilisia, 2011).

So how did we approach this in the research project? We knew that the welfare services provided to South Sámi could be influenced by the effects of the Norwegianization processes. These effects include discrimination, patronisation, and colonisation and could appear when developing 'respectable' services for the Sámi in South Sápmi. This is because welfare service methods usually are adapted to the majority populations, and to the contexts and cultures that represent the majority community (Gray, Coates, \& Bird, 2008). Practices and services adapted to indigenous peoples and minorities were therefore still needed. We also knew that the worldview of South Sámi contained strong lines of demarcation, including being 'different' from Norwegians. South Sámi culture also holds collective memories of historical discrimination from Norwegianization or colonial politics and policy (Hedlund \& Moe, 2010). We, however, did not take fully into account the important issue of identification. Modern societies provide better opportunities for individuals to define their own identity. Decades of colonial Norwegian policies have, however, led many Sámi to conceal their Sámi background and present themselves as Norwegian (Bjørklund, 2016). There is still no public record of who is Sámi beyond the Sámi census, which is not available to researchers (Pettersen \& Brustad, 2013). Being Sámi can today be understood to be a feeling of belonging. For some, this is something that is only expressed in certain cultural spheres. For others, it may involve social interactions in which Sámi cultural competence dominates, such as in some core Sámi areas. There is therefore an on-going 
discussion on whether Sámi identity is defined through self-identification, or by an essential definition based on biological criteria (Bjørklund, 2016).

\section{THEORETICAL PERSPECTIVES ON DECOLONISATION AND REALITY}

The research project focused on the issues of interaction in welfare services between non Sámi origin providers and those of South Sámi origin, and how power mechanics and dynamics were involved in the interactions (Hedlund \&Moe, 2010). Norwegians historically exerted a dominant ideology and suppressive policies upon the Sámi, neglecting indigenous culture, priorities and differences. This created Sámi as a non-issue or what is called a 'structured absence' (Morley \& Chen, 1996). These policies operated, for example, to assimilate Sámi people through education programmes and through institutions that forced them to adopt Norwegian language and culture, this erasing Sámi traditions, language and way of living. Both the church and state education system were active arenas for Norweganisation policy. The Norweganisation policy towards Sámi should represent a former historical phase of public policy in Norway. We, however, stated in the research that this still could cause on-going suppression and dominance by Norwegians when providing welfare services to Sámi (Hedlund \& Moe, 2010). Nevertheless, we did not take fully into account the implications of Sámi as an underprivileged group. According to Smith (1999), underprivileged groups and categories in society may represent alternative societal perspectives, and may mobilise based on other grounds than those of a privileged group. We did not consider this aspect when carrying out our analysis in the research project. If we had, we would have known that Sámi may ontologically have a different worldview of the reality of representing an underprivileged group than that defined by the privileged groups. The worldviews of Norwegians and Sámi may conflict. We should therefore have approached this issue more systematically. The recognition of such conflicting views may, methodologically, call for a particularly sensitive epistemology in research, according to Kuokkanen (2010). It is therefore important to act as responsible academics towards indigenous epistemes.

Kuokkanen (2010) claims that researchers should recognise their responsibility when collecting data, interpreting and analysing, and when discussing results. Researchers should know that 'blind spots' are likely if the research does not seek to dismantle oppressive, hegemonic structures in society (Kuok- 
kanen, 2010). Researchers should also be aware that this may lead to superficial analysis and a continuation of implying colonial perspectives. An alternative strategy could be that academics critically examine their worldview and how it informs the interpretation process and the worldview of those investigated. This is a part of doing the homework, according to Kuokkonen (2010, p.61):

Calling for the responsibility of the academy to do its homework pertaining to indigenous epistemes is part of the larger project of shifting the attention from common institutional approaches seeking to mainstream and "acclimatize" indigenous students to the culture and convention of academy to investigating the role of the academy with regard to other and its own foundational epistemes in its production and politics of knowledge.

From this we can learn that any researcher, whether they have an indigenous background or not, should reflect more on these issues and their own ontological and epistemological position when conducting research. Kuokkonen (2010) suggests that it is necessary to explore multiple views on reality, and bring to the surface discrete, implicit or hidden worldviews if, that is, we are to understand the situated practice of interactions in any research project. A substantial difference in the view of the world and reality will co-exist, but may be easily kept hidden if this is not reflected upon during the research process.

We wanted, in the research project, to analyse differences of reality between South Sámi and Norwegians. We, however, approached it more as a difference in culture and understanding than an epistemological position. We did not intend to merely 'reduce' people to 'culture' when carrying out the analysis. We wanted to capture the situation and experience of the interactions and differences between South Sámi users and Norwegian health and welfare service providers. However, rethinking the methodological approach we used in the project, we can comprehend that we could more explicitly have used a methodological approach that was oriented towards capturing the differences of reality between Norwegians and South Sámi. We realise that previous conflicts relating to resources, land use, experience of racism and exploitation could lead South Sámi to experience a struggle in relation to the right of 'being Sámi'. Sámi knowledge and the experience of reality could be lost in interactions with Norwegians. Any epistemology will, in this way, not imply that it is equivalent to 'culture' when carrying out research on South Sámi and 
Norwegians. Nor will it represent an epistemological turn of sophisticated techniques to claim that essentialism is the only thing that matters, nor that all ethnographic narratives are homogeneous. The epistemological viewpoint suggests, for the research project discussed here, an analytical framework for radically rethinking which is different from that we carried out methodologically.

As researchers, we should have paid more attention to the situated practice between South Sámi people and Norwegians when they gave us information about their experiences and interactions. We should have approached the data more as expressions of different life worlds, and not just different experiences and cultures. As researchers, we should have paid more attention to power asymmetries than we did. We should not only address this as we would any asymmetric relationship of the actual interaction, but as asymmetries that appear due to different worldviews and experiences, and/or based on historical events and collective memories of interactions in which people from different cultures are not treated alike.

Burman (2016) claims that the knowledge and realities from these different cultures, in modern societies and contexts in which different cultures and people are present and co-exist, are mutually formative, playing major roles in constituting each other. Burman (2016) argues that this makes people a part of power-infused dialectics of reality and knowledge/reality for generations. Colonisation therefore, according to Burman (2016), does not refer to just the material condition of one category of people taking over a geographic landscape, and of dominating and discriminating people who were originally in this geographic landscape and location. Colonisation instead refers to the process of one society of people colonializing another society, and the reality of the life world. This was a fruitful approach to research project analysis. The self-identification of Sámi people and being one people is challenged or threatened in historical epochs of colonisation. This fact could have been more actively used in the research project. We as researchers should, to allow for a more decolonising approach, have reflected more critically on how these issues interfered with and influenced the research project. We could, for example, have had a stronger focus on the impact upon the South Sámi of being empowered and using the knowledge we produced in the research project. We did ask Sámi users to speak freely about life worlds and understandings of reality when we asked interview guide questions. We also tested the research guide and questions with key informants from the South Sámi community before we carried out the interviews. We used this strategy to try to recog- 
nize and incorporate knowledge from the South Sámi communities and use our knowledge from Norwegian communities that are within a similar landscape as the South Sámi. In this way, as Olsen (2016) emphasizes, we tried to avoid colonializing the minority in the first place. We could, however, have better grasped a different epistemological approach if we had used an institutional ethnographic approach and more critically used a decolonial theoretical approach in the research project.

\section{INSTITUTIONAL ETHNOGRAPHY AS METHODOLOGICAL APPROACH}

Institutional ethnography as a methodology could have been a rewarding alternative approach in the research project. We therefore here discuss the implications of using this approach in the research project. Smith (2005) describes institutional ethnography as a methodology for creating knowledge that is situated within individuals and their relationships.

One condition for carrying out an institutional ethnographic analysis is that people should be approached as social subjects, who actively interact with their environment and who through these interactions acquire knowledge and understanding of their everyday life. Knowledge about human life and social relations emerges by directing the research towards people's activities and actions, relationships and action chains. Such a focus also provides knowledge about the environments of everyday human activity. Researchers who undertake such work are less interested in observing and gathering data about humans, and more interested in observing and gathering data for them and with them. This represents a shift in the research focus, from being on people as cultural objects and their attitudes and characteristics, to what people can tell us about the activities and relationships they perform in their lives. This causes the subjects to objectively become something that creates a distinction between the researchers and the community, which is experienced as 'othering'. Transferring this to the research project, this implies that the research should try not only to study and chart social activities, but also search for information on how these social activities were coordinated into the 'reality facts' and everyday life problems. In this way we would have been able to study chains of activities that showed patterns of relationships, not only in the home and in the interactions with Norwegian welfare state service providers, but also how these activities worked elsewhere and with other people (Widerberg, 2015). In retrospect we see that such an approach would have made it possible 
to analyse patterns of actions and relationships that were woven into social power structures.

Using institutional ethnography as a methodological approach would have made it possible to analyse data and rethink interpretations about situational knowledge to a greater extent than we did. This approach would also have made it possible to analyse and connect more to topics such as ethnicity, gender, class and power in our analysis.

\section{METHODOLOGICAL ISSUES ADDRESSED IN THE STUDY}

We, as researchers, knew about the long-term Norwegian politics and the suppression of indigenous people. This forms the starting point of the research project discussed here, and its original design. To learn more about this, we contacted representatives of a South Sámi cultural centre to discuss design, methods and criteria of recruitment. We also carried out interviews with key persons and tested interview guides, before starting to collect data. All key persons had a South Sámi background, and the study was met with interest and also scepticism when introduced to representatives of the South Sámi culture centre. The scepticism related to the concern of whether any ethnic Norwegian researcher could carry out a project on welfare services among South Sámi users. They questioned whether South Sámi would be able to convey their experiences to researchers who represented the majority in the community. On the other hand, we experienced interest in the research project topic and the importance of looking into these questions by skilled researchers, regardless of ethnic background. There were no skilled researchers with a background from South Sámi communities who would agree to assist with the research project. We, however, kept in touch with trained health and social service professionals during the research period, with key persons within South Sámi communities and members of the advisory board. They were not employed as or were skilled researchers, but added important value and guidance to performing the research.

The advisory board included welfare service providers with South Sámi backgrounds (recruited through the state regulatory authority for primary services in the region) and persons with particular knowledge about South Sámi culture (recruited through a southern Sámi cultural centre). Discussions held in the advisory group provided guidance on the difficulties that ethnic Norwe- 
gian researchers might encounter in the implementation of the research, and how these difficulties could be met. One issue that was discussed was how to take great care and be aware of the choices made during the research process, that could cause harm or be oppressive to South Sámi. The input from the advisory group had a decisive impact on how recruitment and access to data was managed. We, as researchers, even so had to continue to own the responsibility for the choices made on research design and issues. We decided, after discussions in the research team and in the advisory board, which municipalities with South Sámi settlement were of interest. We contacted the administration in the municipalities to clarify who might be relevant to interview. We then contacted the relevant service providers directly and made appointments with them. These service providers had different positions and responsibilities within the municipal welfare services. Their experiences therefore applied to a wide range of welfare services offered to South Sámi within the municipality.

\section{THE RESEARCHERS' POSITION}

As researchers, we were responsible for fulfilling the expectations and the research mission of the funder of the research, the Sámi Parliament. We were also anxious that we did not take on a research position that was associated with previous Norwegianization processes and discrimination of South Sámi. As researchers, we instead chose to adopt a position of solidarity, which led us to be humble in our contact with our South Sámi users. We were aware that we as researchers represented the majority population, and that we were asking for input not only to the research questions, but also on the South Sámi situation in general. We therefore tried to show enthusiasm when meeting South Sámi and to demonstrate our willingness to learn, when carrying out the study. We, as researchers, therefore adopted the position of learning. A weakness of this approach could be that we did not clarify that the research project did not involve researchers from South Sámi backgrounds.

We found it useful to introduce ourselves both as Norwegians and persons with private life experiences and stories. We both experienced it useful to use our local identities as women who had grown up and lived in the same geographical locations as South Sámi settlement, and therefore had local knowledge. By revealing our family backgrounds from the same geographical areas, we asked questions that demonstrated local knowledge about locations and South Sámi settlements. One of us had personal experiences from a marriage 
with a person with an indigenous background from another country. This was also introduced in the interview situation. As researchers, we learned that it was important to introduce ourselves as persons, and not only as researchers. This led to several interviewees wondering about our local knowledge and who we were. One researcher told about a childhood visit to their family, and a father who was known in the area. A South Sámi interviewee from the older generation then exclaimed: Why didn't you say who you are? Another said: As I know who your father is, then it's almost like I've always known you. In both situations, the interviewees became more talkative about their experiences with welfare services when they knew the researchers' family backgrounds. Another experience arose when telling the story of a researcher having knowledge of a country far away, in which there was a dominance of indigenous people. This made interviewees more willing to talk about their experiences. One interviewee replied: So, you know about being different and how indigenous people think. Why didn't you say so in the first place? Our experience was, on several occasions, that the introduction of our personal experiences was a useful way to get South Sámi persons to talk in the interviews. Nevertheless, we did not situate us as in conflict with South Sámi traditions and culture as researchers with a Norwegian background. If we had done this, then maybe we would have received other stories and data. We were told in some interviews that it was an advantage that we did not have a Sámi background, as they then could speak freely about the problems they experienced in the family or with their background without the fear of others being able to identify who they were talking about.

\section{WHAT DID WE LEARN FROM THE CONDUCTED STUDY?}

One finding of our study was that South Sámi users talked about experiences of encounters with Norwegian health and welfare service providers from a more general perspective, and did not always refer to specific encounters. They instead reported about complicated everyday lives in which they strive to maintain Sámi culture and traditions, and the lack of understanding of this among Norwegian people in general. Some talked about experiences and the importance of maintaining an attachment to reindeer husbandry. They emphasised how reindeer husbandry could be a very physically demanding occupation, and that it lacked the ability to meet the needs of a society that 
did not know about this industry's conditions. Some service providers replied that they understood this. They also praised South Sámi users for not using the welfare services more than necessary and only when needed. When they sought help, users really needed help for specific and very concrete conditions. South Sámi did not address diffuse problems, according to Norwegian service providers. We ended up in our original analysis of the data describing encounters between service providers and users as being 'good' or 'bad'.

A quote from a health worker was found to illustrate a pattern in the data that relates to these 'bad' or 'good' encounters. This is a category we labelled: South Sámi are the perfect patients. This refers to service providers characterising South Sámi users as 'perfect', as they sought help for acute and specific health issues. This was confirmed by descriptions of South Sámi users. A 'bad' encounter would appear when South Sámi users experienced misunderstanding or lack of access to the help they required. One user shared a story describing such experiences. This took place when a husband, whose occupation was reindeer herder, told about his difficulties supporting his wife when she consulted a doctor, despite his intended to support her:

I got told off by the doctor, who believed I [voluntarily] stayed at home. I said nothing, because I knew it was something the doctor wouldn't understand. There is no point trying to explain something that they are never going to understand.

Here the user referred to an episode in which he, due to changing weather conditions, had to go out to the mountain to herd his reindeer. If he did not, he would have risked losing the animals due to the bad weather and grazing conditions. This meant that he could not accompany his wife to the doctor, something he experienced the doctor could not understand. When we analysed this as an illustration of a 'bad' encounter, we could see that we had not dug sufficiently into the 'reality' and opposing world views of the reindeer herder and the doctor. It illustrated a far more complex interwoven power structure than the initial analysis showed it to be. The powerlessness the South Sámi user expressed was not an illustration of 'bad' encounters, in which the needs of South Sámi users where not met by a Norwegian doctor. It was an expression of the long period of Norwegian health worker lack of understanding and the development of a more collective Sámi 'pain' from suppressive Norwegianization policies that overpower Sámi traditions and culture. 
If we had used a more institutional ethnographic methodology in this research project, then we probably would have assessed different data. Not just interviews, but also observations. This would have allowed us to obtain more data about complicated everyday life issues and the difficulties associated with South Sámi communities getting a voice in Norwegian society. Using an interactionist perspective in analysis, taught us that everyday life could be difficult. We did not, however, understand how these difficulties played out. If we had explored more data on everyday activities, such as who was responsible for what in the home and in reindeer husbandry, both in ordinary day-to-day life and during illness or other events, then we could have accessed a deeper knowledge on managing stress and making life valuable, despite the stresses of everyday life. The social relationships included in activities would also have emerged. Analysing everyday activities and relationships might have clarified how the structures of society were articulated in the Sámi husband having to travel to the distant mountains when his wife was sick. The regulation of grazing areas and the profitability demands of reindeer husbandry, plus the lack of support schemes, forced him to prioritize reindeer husbandry over visiting the doctor and learning what was best for his wife at home. The crucial importance of reindeer husbandry to the continuation of South Sámi culture and tradition shows how this responsibility is privatized and poses challenges in the day-today life of South Sámi. The distance between reindeer grazing areas, the profitability demands and size of reindeer herds, and access to home services are the result of political decisions in a society that both affect and play out in everyday activities. This information would have provided knowledge on the relationship between South Sámi's everyday lives and how the structures of society contribute or hinder cultural continuation, including how welfare services work.

The difficulties associated with maintaining South Sámi identity in old age through embracing simple cultural expressions, is another illustration of our original analysis becoming too narrow. A South Sámi interviewee with experience as a familial caregiver visitor to South Sámi residents in a municipal nursing home, told about a nursing home ignoring South Sámi culture:

... this includes decorations, what about a coffee bag and a kettle on the wall? Something South Sámi would recognize. But no. At the nursing home it doesn't just have to be [Ethnic Norwegian] farm food and farming pictures. ... Sámi must also be offered food we like and are used to, reindeer meat and bone marrow broth. This should be done. 
... We must be allowed to be Sámi when we are sick too ... This statement was made in association with the story of an elderly man who was frail, and had been staying in a care home. He had placed his knife under the pillow on his bed, so that it was always close by. The knife had always been a companion that he had used in many activities in everyday life, and he felt naked without it. The traditional South Sámi knife under a pillow was the subject of much discussion among caregivers in the home, who thought this should be banned in a nursing home setting.

We interpreted these descriptions as illustrations of service providers' lack of understanding and sensitivity to South Sámi practices or traditional ways of knowing. This therefore contributed to South Sámi having little opportunity to maintain traditional practices of healing and health when they were dependent on living in nursing homes. If, as researchers, we had focused on what South Sámi experienced as being difficult in their day-to-day lives, on the activities people wanted to do and how this could be solved, we would have gained more knowledge about the social reality they face and the type of dominant structure they met in encounters with Norwegian welfare service providers.

We also did not provide general descriptions and conditions of the dayto-day professional lives of service providers. We restricted ourselves to focusing on their experiences with South Sámi users. Service providers' knowledge and expertise, structural framework conditions and opportunities to provide custom services were aspects we only focused on to a small extent. When we discovered that nursing homes were characterized by the cultural dominance of Norwegians, we interpreted this to mean that caregivers showed little understanding of South Sámi culture and traditions, which in turn had a definitive impact on the design of services for South Sámi. As we discussed here, we could have interpreted this as an expression of South Sámi as victims of discrimination, with less power to fight structures of dominance of the Norwegian culture. 


\section{DISCUSSION}

We argued, in the introduction to the article, for the need to rethink theoretical framework and methodology when carrying out research in South Sámi communities. All research involves the choice of a methodology. Our research into welfare services provided to the South Sámi population in Mid-Norway, was originally based on an interactionist perspective. This gave us knowledge on key issues that were relevant to understanding the interaction between South Sámi users of services and Norwegian service providers. We, however, retrospectively understand this was not the complete analysis. We therefore rethought the methodological approach, to find a methodology that would allow us to study the complex power structures involved, both in our approach and in the data and in the analysis we carried out. We in this article, through analysing the study retrospectively, critically reflect on our experiences and choices as researchers, and what we found when carry out the analysis. We realize that there is a need to rethink when carrying out this type of analysis and approach. Research must not only be reflexive about power structures and decolonisation of indigenous knowledge, but also develop strategies that avoid adding to an oppressive experience in South Sámi communities. Institutional ethnography as a methodology could provide access to more complementary data sources on everyday life, action chains and problematic social relations. If we had more closely followed up (in interviews and observations from South Sámi communities) these actions and social relationships, and the problems they cause people in day-to-day life, then we might have found out more about the realities of importance to South Sámi people and the struggle against Norwegian ontological dominance. It may have been possible to analyse how welfare services provided by Norwegians to Sámi were dominated by Norwegian culture and less open to the needs and problems of the everyday lives of South Sámi users. We, as scientists, were very aware of our identification as representatives of the majority community by South Sámi, and tried to take very great care to not behave in a patronising and/or discriminating way when collecting data. This was, however, not enough. Today we see that the chosen methodology helped us to disguise and repress hidden power relationships and social structures that affected South Sámi everyday lives and context. These are the structural conditions that govern relationships in everyday life. Here they result in a complicated and cumbersome life, with difficult access to 
welfare services and a welfare service that does not take into consideration the everyday life of South Sámi culture.

Any methodology has its strengths and weaknesses. Proximity to the field of research may be an advantage in data interpretation. It may, however, also lead to 'blind spots' in the research (Wadel \& Wadel, 2007). It is argued that ethnicity is important to understanding culture. It can also be argued that ethnicity is important in the choice of methodology in a research process (Heikkilä, 2016). Patton (2002) talks about the importance of situating the 'self' and thinking about one's role as a researcher in planning and conducting qualitative research. Researchers, during the planning and conducting of research and to various degrees, participate in the daily life or activities of the world that is studied. This ranges from full participation in periods, to complete observation where the researcher does not participate in any social interaction or actions in the world or reality that is studied. This is doing your 'homework' as suggested by Kuokkonen (2010). Interviews as data may not fully represent observational data. Complete observation may also not fully reveal the reality of the focus in the research. Researchers need to consider all these aspects, even when using an institutional approach and methodology. Cultural beliefs and values may, however, be hierarchical and collectivistic in research. In the research we refer to in this chapter, high levels of awareness and situating both of the researchers and the participants in the research is necessary.

The study we discuss in this article was carried out using limited resources and to deadlines. This meant that there was a limited scope to mobilize and engage South Sámi persons to participate more in different study processes. Despite these shortcomings, the study helped to ask questions about welfare services for South Sámi people and to put this on the agenda in South Sámi and Norwegian contexts. This study therefore produced knowledge about Sámi diversity in welfare and health. There are knowledge organizations in core areas of Sápmi in the north that are particularly concerned with questions of ethnicity, indigenous people, welfare and health. This is absent in the south. The disparity between relevant knowledge development in the north and south may also be a sign of dominance and power structures within the larger Sámi community. Future research should therefore seek to engage constructive contributors to provide knowledge, from which both the larger Sámi community and the South Sámi community can benefit.

Further lessons learned from reanalysing the methodology used in our research into welfare services for South Sámi, relate to aspects of othering. The 
idea of othering represents an important aspect that extends across the use of all qualitative methods. In particular, where the intensity of the interviewer-interviewee relationship is vital to the quality of outcomes (Olsen, 2016). The notion of othering is of particular relevance when using institutional ethnography as a methodology. In this approach, the researcher must pay particular attention to whether he or she is an instrument. A hidden 'asymmetrical power environment' may appear between the interviewer and interviewee, which allows the researcher to make certain assumptions (and possibly misperceptions) about the interviewee. These preconceptions ultimately play a role in the final interpretations, influencing the interpretation and reporting of data. Research represents a potentially uneven power relationship in which reflexivity is essential, particularly when the goal of the research is advocacy and action for an unprivileged group. This was the case for us as researchers looking into South Sámi as welfare service users.

It is not enough for researchers to simply situate themselves and their research role when conducting this type of qualitative research. The researcher must also see and analyse themselves and the setting of the research. Participants' willingness to engage and answer the questions asked, and whether the researcher receives a thoughtfully reflexive response, may be evidence not only of whether the questions are relevant, but also represents a message about differences, power, and structural relationships. One criticism of research conducted by Norwegian people in South Sámi communities is the use of perspectives and worldviews commensurable with 'Norwegianization' discourses. They thereby fall into the loop of what Smith (1999) warns can promote an imperialistic way of understanding indigenous people and worldviews. It is crucial, as we illustrate in this article, for researchers belonging to the majority population of Norwegians to free themselves from the previous sins of their ancestors, and from the discrimination they inflicted (Gray, Coates, \& Yellow Bird, 2008 ). The researchers must also take on board the call to 'do your homework' (Kuokkanen, 2010) to avoid the temptation to be a representative of colonial containment. Such an approach would, when applied to research in South Sámi communities, entail that the South Sámi indigenous knowledge system was utilized more in the research process and that South Sámi knowledge played a more important role in the study. Researchers must also work analytically with their own cultural competence and knowledge during the research process. Information and knowledge on different issues relating to power structures and problematic lives needs to be followed up and situ- 
ated during data collection and analysis. If not, there is a risk of conducting research that 'objectifies' the reality of South Sámi and remains ignorant to the cultural and structural context. Researchers likewise need to situate their research, to find the arguments for conducting choices in research and for the consequences of these choices. Methodologies, what types of knowledge and interpretive framing inform the research, and choices of methods and procedures should be critically examined, and researchers should demonstrate reflexivity when evaluating whether the data generated is appropriate for addressing the research questions. There is often a problem in studies of ethnicity, gender, and/or minorities of whether a researcher can provide valid knowledge of 'the others' without belonging to that category themselves, or where they represent dominating and suppressive power structures. The researchers' ability to be reflexive about methodology and re-define their power position when conducting the research, is likely to be the best way of using de-colonising methodologies in such studies. We have therefore argued that different values, life worlds and realities can be captured and explored using interactionist perspectives to study encounters between South Sámi users and Norwegian service providers. However, such perspectives will likely continue to conceal complex power structures. Research imbued with an attitude which assumes certain power structures, proclaims an ownership to the reality in the world. It is also heavily biased toward institutional research practices embedded in the dominant culture and not in the culture and everyday life of the people being suppressed. To capture this reality and these problems, researchers must be aware of the colonising gaze that they continue to possess as researchers from a majority ethnic group, and to further justify the lifting of indigenous peoples' critical voices towards the dominant society. 


\section{REFERENCES}

Bjørklund, I. (2016). “Er ikke blodet mitt bra nok?” Om etniske konstruksjoner og identitetsforvaltning i Sápmi. Nytt norsk tidsskrift, 33(1-2), 8-20. https://doi.org/10.18261/issn.1504-3053-2016-01-02-02

Blix, B. H., Hamran, T., \& Normann, H. K. (2013). Struggles of being and becoming: A dialogical narrative analysis of the life stories of Sámi elderly. Journal of Aging Studies, 27(3), 264-275. https://doi.org/10.1016/j.jaging.2013.05.002

Burman, A. (2016). Damnès realities and ontological disobedience. In Grostfognet, E. (Eds.). Decolonalization the western universities - intervention of philosophy of education from within and without. London: Lexiton books.

Chilisia, B. (2011). Indigenous Research Methodologies. Los Angeles: Sage.

Daerga, L., Sjölander, P., Jacobsson, L., \& Edin-Liljegren, A. (2012). The confidence in health care and social services in northern Sweden - a comparison between reindeer-herding Sámi and the non-Sámi majority population. Scandinavian Journal of Public Health, 40(6), 516-522. https://doi.org/10.1177/1403494812453971

Fjellheim, E. M. (2013). Utmarkskonflikt i Sør-Samisk område: Etnisitet, identitet og rettigheter. Plan (03), 28-31.

Furberg, M., Evengård, B., \& Nilsson, M. (2011). Facing the limit of resilience: perceptions of climate change among reindeer herding Sámi in Sweden. Global Health Action, 4(1). https://doi.org/10.3402/gha.v4i0.8417

Gauslaa, J. (2005). Lov om reindrift: 9. juni 1978 nr. 49. Norsk lovkommentar / hovedredaktører: Peter Lødrup, Knut Kaasen, Steinar Tjomsland, [B.] 1, 1259-1274.

Gray, M., Coates, J., \& Yellow Bird, M. (2008). Indigenous social work around the world: towards culturally relevant education and practice. Aldershot: Ashgate.

Gremsperger, A. (2012). On the Sámi minority. In Jura (Eds.). A Pecsi Tudomanyegyetem Allam- es Jogtudomanyi Karanak tudomanyos lapja (p. 135). Pecs, Hungary: University of Pecs.

Hedlund, M., \& Moe, A. (2000). "De forstår ikke hva som er viktig for oss": helsetjenester og sørsamer. (Vol. 2000:2). Steinkjer: Nord-Trøndelagsforskning.

Hedlund, M., \& Moe, A. (2010). Redefining relations among minority users and social workers: Redefinisjon av relasjoner mellom brukere med minoritetsbakgrunn og sosialarbeidere. European Journal of Social Work, 13(2), 183-198. https://doi.org/10.1080/13691451003690924 
Heiervang, K. S., Mednick, S., Sundet, K., \& Rund, B. R. (2011). The psychological well-being of Norwegian adolescents exposed in utero to radiation from the Chernobyl accident. (Research)(Report). Child and Adolescent Psychiatry and Mental Health, 5(12). https://doi.org/10.1186/1753-2000-5-12

Heikkilä, L. (2016). Welfare services in enhancing good life for the Sámi: A reflection on conducting ethically responsible research and developing an improved sense of culture. International Social Work, 59(5), 653-665. https://doi.org/10.1177/0020872816646819

Hilmo, J. V., \& Mæhlum, B. (2012). Språksamfunn i grenseland: Ein sosiolingristisk studie av språk og språkoppfatningar i Tydalen. Norges teknisknaturvitenskapelige universitet, Det humanistiske fakultet, Institutt for nordistikk og litteraturvitenskap.

ILO (International Labour Standards Department) (169) Indigenous \& Tribal Peoples' Rights in Practice: A Guide to ILO Convention No. 169.

Jernsletten, J. L. (2009). Bissiedajue. Relasjoner mellom folk og landskap i VoengelNjaarke sijte. Ph.D. thesis. Tromsø: Universitetet i Tromsø.

Johansen, I. (2006).. Norges teknisk-naturvitenskapelige universitet, Det humanistiske fakultet, Institutt for nordistikk og litteraturvitenskap. Kuokkanen, R. (2010). The Responsibility of the Academy: A Call for Doing Homework.JCT (Online), 25(3):61-74. E-ISSN:19422563.

Mathisen, L., Carlsson, E., \& Sletterod, N. A. (2017). Sámi identity and preferred futures: Experiences among youth in Finnmark and Trøndelag, Norway. (Report). Northern Review (45), 113. https://doi.org/10.22584/nr45.2017.007

Ministry of Agriculture and Food (2019). Reindeer husbandry. Downloaded 24/11/2019 from Government.no https://www.regjeringen.no/en/topics/foodfisheries-and-agriculture/reindeer-husbandry/reindeer-husbandry/id2339774/ Ministry of Work and Integration [AI, Arbeids- og Inkluderingsdepartement] (2009). Handlingsplan for Samisk språk. Oslo.

Morley, D. \& Chen, K. H. (1996). New ethnicities. In Morley, D. (Eds.). Stuart Hall: Critical dialogues in cultural studies. London: Routledge.

Morris, K. (2009). Loss of land could threaten health of Sámi people. The Lancet, 374(9683), 15-16. https://doi.org/10.1016/S0140-6736(09)61219-8

NOU (1995). Plan for helse og sosialtjenester for den Samiske befolkning i Norge, nr. 6 [Planning Health and Social Services for the Sámi Population in Norway, no. 6]. Oslo: Sosial- og helsedepartementet.

Nystad, T., Melhus, M., \& Lund, E. (2008). Sámi speakers are less satisfied with general practitioners' services. International Journal of Circumpolar Health, 67(1), 116-123. https://doi.org/10.3402/ijch.v67i1.18246 
Olsen, T. A. (2016). Responsibility, reciprocity and respect. On the ethics of (self-) representation and advocacy in Indigenous studies. Sámi dutkan - Samiska studier - Sámi studies 2016(7), 25-44.

Olsen, T. A. (2016). Kjønn og urfolksmetodologi. [Gender and indigenous methodology]. Tidsskrift for kjonnsforskning, 40(2), 87-103. https://doi.org/10.18261/issn.1891-1781-2016-02-02

Patton, M.Q (2002). Qualitative research and evolution methods ( $2^{\text {nd }}$ ed.). Thousand Oaks, CA: Sage.

Pettersen, T., \& Brustad, M. (2013). Which Sámi? Sámi inclusion criteria in population-based studies of Sámi health and living conditions in Norway - an exploratory study exemplified with data from the SÁMINOR study. International Journal of Circumpolar Health, 72(1). https://doi.org/10.3402/ijch.v72i0.21813

Sámi Parliament [Sametinget] (2019) Downloaded 15.11.2019 from Sametinget.no https://www.sametinget.no/Tjenester/Spraak\#sectionForvaltningsomraadet-for-samiske-spraak

Sámien Sitje (2018). 'Det Sør-Samiske område'. Downloaded 04/01/2018 from: https://saemiensijte.no/om-sorsamer/

Sehlin MacNeil, K. (2015). Shafted: a case of cultural and structural violence in the power relations between a Sámi community and a mining company in northern Sweden. Ethnologia Scandinavica, 45, 73-88.

Smith, L. T. (1999). Decolonizing methodologies: research and indigenous peoples. Dunedin: University of Otago Press.

Smith, D. E. (2005). Institutional ethnography: a sociology for people. Lanham, Md: AltaMira.

Steinfell, R.B. (2014) 'Taking our language back home'- Motivation and challenges in the South Sami area. Master Thesis in Philosophy in Indigenous Studies. Tromsø: UiT, The Arctic University of Norway.

St. meld. 13 (2011-2012). Utdanning for velferd. Oslo: Kunnskapsdepartementet. Todal, J. (2005). Når er eit språk forsvunne? Kritiske merknader til språkdødmetaforen. I Väimmus čiegan sániid - I hjärtat gömmer jag orden. Larsson L.G., Söder, T. (red.) Uppsala: Institutionen för moderna språk, Uppsala universitet.

Wadel, C., \&Wadel, C. C. (2007). Den samfunnsvitenskapelige konstruksjon av virkeligheten (3. utg. ed.). Kristiansand: Høyskoleforlaget.

Widerberg, K. (2015). I hjertet av velferdsstaten: en invitasjon til institusjonell etnografi. Oslo: Cappelen Damm akademisk. 